UDK 72.012:004.925.8

Original scientific paper

\title{
THE SUSTAINABLE INTELLIGENT BUILDING SKINS -FACADE IMITATING THE TREE PROCCES OF FILTERING AIR, BIOMIMICRY ARCHITECTURE
}

\author{
Eneida HASKA ${ }^{1 *}$, Halil Semih ERYILDIZ ${ }^{1}$, Hajri HASKA ${ }^{2}$
}

\begin{abstract}
In recent years the facades of building have become incrisingly significant due to unconvencional choices of materials and the use of inovative technology. More and more the external surfaces are beeing percived and designet as an integral part of the building. This skin, a protective mantle defines not only the interior but also the adjoining exterior space. It is visiting card of the building. Today's way of doing architecture should be a vision initiative which includes new ways of thinking about the relationship between construction and the environment, discovering new forms and content, and the assertion that the art of construction is in a new phase which will definitely change the way of our living, always in accordance with the language of nature. In this study we will show examples of how new forms of architectural design imitating nature completely change the old fashioned way of design. Especially Intelligent Façade which is a very efficient form of our impact in nature.
\end{abstract}

Keywords: green smart skins, adaptive building façade, filtering polluted air, tree imitation

\section{INTRODUCTION}

The 20th-century architecture began as a manifestation of the era of industrialization and technology, but in the 1990's it began to change rapidly with a new era of information and ecology. One of the most complex and problematic issues facing mankind in the following century is how to construct a habitat in

\footnotetext{
${ }^{1}$ Okan University, Faculty of Architecture and Design, Istanbul, Turkey

2 3Agriculture University of Tirana, Faculty of Forestry Sciences, 1029 Tirana, Albania

*e-mail: eneidahaska@outlook.com
} 
harmony with nature, always having in mind a creative dialogue and not a choice that would be Utopian. By the time Late Modern reached its predominant influence, the parallels between industrial production and expression in form were very easily understood. Similarly, the end of the 20th century created very strong evidence of environmental / environmental technology and natural landscape transformed into architectural iconography of the ecology era. When we talk about, the smart facade skin and building envelope that is able to adapt to environmental circumstances dates back to the first opening. The idea of the smart and sustainable facade has only been around for a few decades, helped along by recent advances in chemical and material science. And over the past ten years we have seen this category boom.

\section{UNDERSTANDING SUSTAINABLE DESIGN}

\subsection{Problems architecture is facing, benefits of sustainable design}

One of the biggest problems facing environmental architecture, leaving aside the lack of a strong social attitude, is a professional choice to over-emphasize the advantages of technology and underestimate the social and aesthetic aspect.

"Architecture has a serious problem today in that people who are not alike don't communicate. I'm actually more interested in communicating with people I disagree with than people I agree with."

"To have a certain virtuosity of interpretation of every phenomenon is crucial. We're working in a world where so many different cultures are operating at the same time, each with their own value system. If you want to be relevant, you need to be open to an enormous multiplicity of values, interpretations, and readings. The old-fashioned Western 'this is' 'that is' is no longer tenable. We need to be intellectual and rigorous, but at the same time relativist."- At the 2016 AIA convention, the legendary architect Rem Koolhaas, the Pritzker Prize-winning Dutch architect gave the profession an honest appraisal of its failures.

The goal that harmonizes this situation is to view environmental technology as a working tool and natural science as a basic source of inspiration. The general categories that can characterize eco-friendly architecture could be defined as follows:

- Mixing landscape architecture,

- Composing or connecting object with garden or environment space,

- Using of the symbolism of nature in order to establish the relevance of architecture to its cultural context

- Support the new acceptance of "green architecture" and the merging of objects in context,

- Far-sighted ideas in architecture and urban planning that provide insight into the future, based on general social and political change that can have an impact on the art of construction and environmental policy, etc.

A number of architects have designed or conceptualized objects that represent striking models of ecological principles, contributing to eco-friendly 
design and high levels of aesthetic design. In such cases it can be understood that the environment / environment is as important as the object, perhaps even more important, because the object must breathe and breathe in the space that surrounds it no matter what it is.

\subsection{Principals creating Architecture}

Throughout the years despite the fact that we had a great deal of changes in innovation, economy, culture and vitality parameters the primary chief in making engineering is as yet structuring and arranging "cover". At the end of the day, the basic point of building is to shield individuals from outer atmosphere conditions, for example, escalated sun powered radiation, extraordinary temperatures, precipitation and wind. In development, the structure skin is the essential subsystem through which winning outer conditions can be affected and controlled to meet the solace necessities of the client inside the structure. Like the skin and dress of people this garment, as well, satisfies the undertakings requested of it by playing out various capacities made conceivable by methods for the proper structure and development.

\section{RESULTS AND DISSCUSION}

\subsection{The Building Skins of the future}

New forms of generating energy will influence the design of the building skin as much as future developments in how we work and live. Actually, the shrewd exterior or building envelope that adjusts to ecological conditions goes back to the main window. In any case, the contemporary thought of the shrewd exterior has just been around for a couple of brief decades, helped along by late advances in concoction and material science. Furthermore, in the course of recent years, we've seen the classification blast.

Underneath, look at probably the most intriguing structure veneers to run over the screen as of late: From a warm metal screen that twists up when it's hot, to a titanium dioxide-secured divider that scours the quality of contaminations.

\subsection{Biomimicry Architecture}

Biomimicry is the impersonation of the models, frameworks, and components of nature to take care of complex human issues; biomimicry in engineering and assembling is the act of planning structures and items that reproduce or co-pick forms that happen in nature. There are ultrastrong manufactured bug silks, glues demonstrated after gecko feet, and wind-turbine cutting edges that copy whale balances. We are living in times where architects and designers through technology can imitate the function of a tree. Through architecture and intelligent building skins we can filter the smog that is damaging our lungs in air. Every big city in the world is affected from smog because of traffic and overpopulation, 


\subsection{A Facade That Eats Smog}

The ascent in air contamination levels is driving a portion of the world's most exceedingly awful influenced urban communities to think about innovative arrangements in building and foundation structure. Air pollution is currently the greatest ecological reason for death, as indicated by the World Health Organization (WHO). Information discharged in 2016, indicated that a stunning 6.5 million individuals kicked the bucket in 2012 because of contaminated air, essentially in and around significant urban communities.

The Western Pacific and South East Asian locales bore the vast majority of the weight with 2.4 and 2.2 million passing, separately.

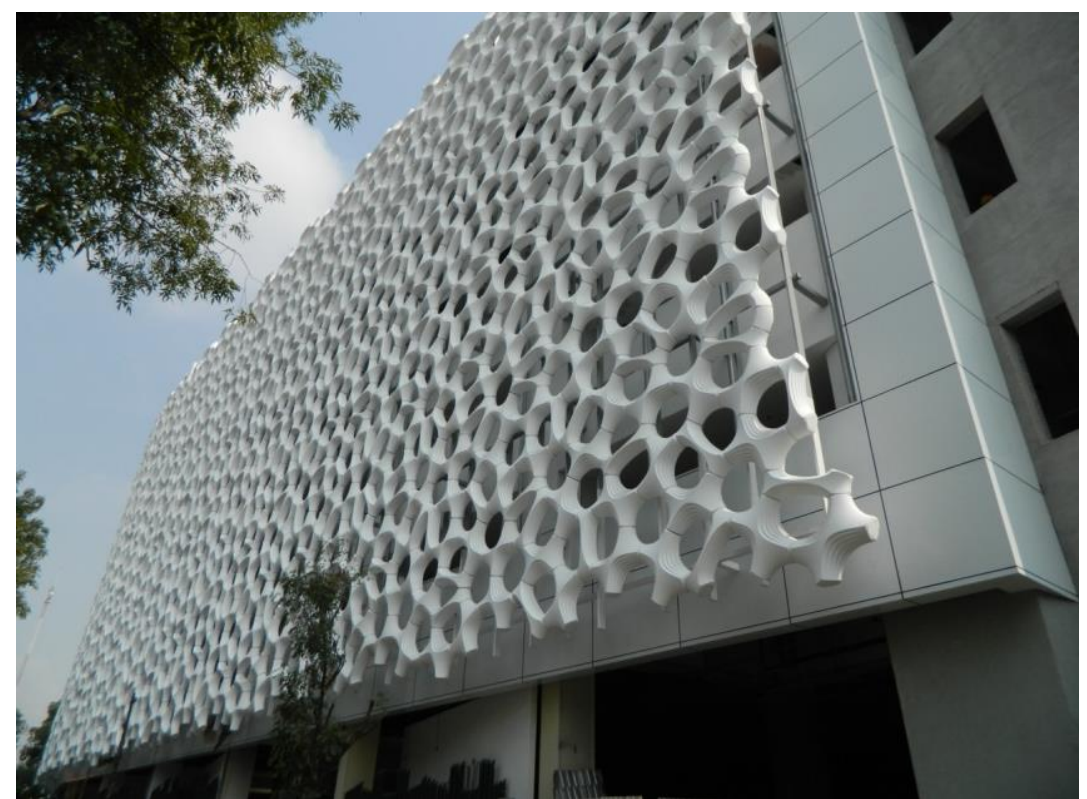

Figure 1. The "smog-eating" installation at Mexico City's Manuel Gea González Hospital (image courtesy of Elegant Embellishments).

While numerous countries are striving to confine emanations regularly in accordance with universal understandings a portion of the most exceedingly awful influenced urban communities are currently looking to mechanical arrangements in building and framework plan.

In 2011, the synthetic organization Alcoa disclosed a momentous innovation that could clean the air around it. The material contained titanium dioxide, which adequately "scoured" the demeanor of poisons by discharging supple free radicals that could dispose of toxins. The stuff has shown up on boulevards, attire, and design from that point forward most as of late, on the sun screen of a New Mexico City clinic, the Torre de Especialidades. 


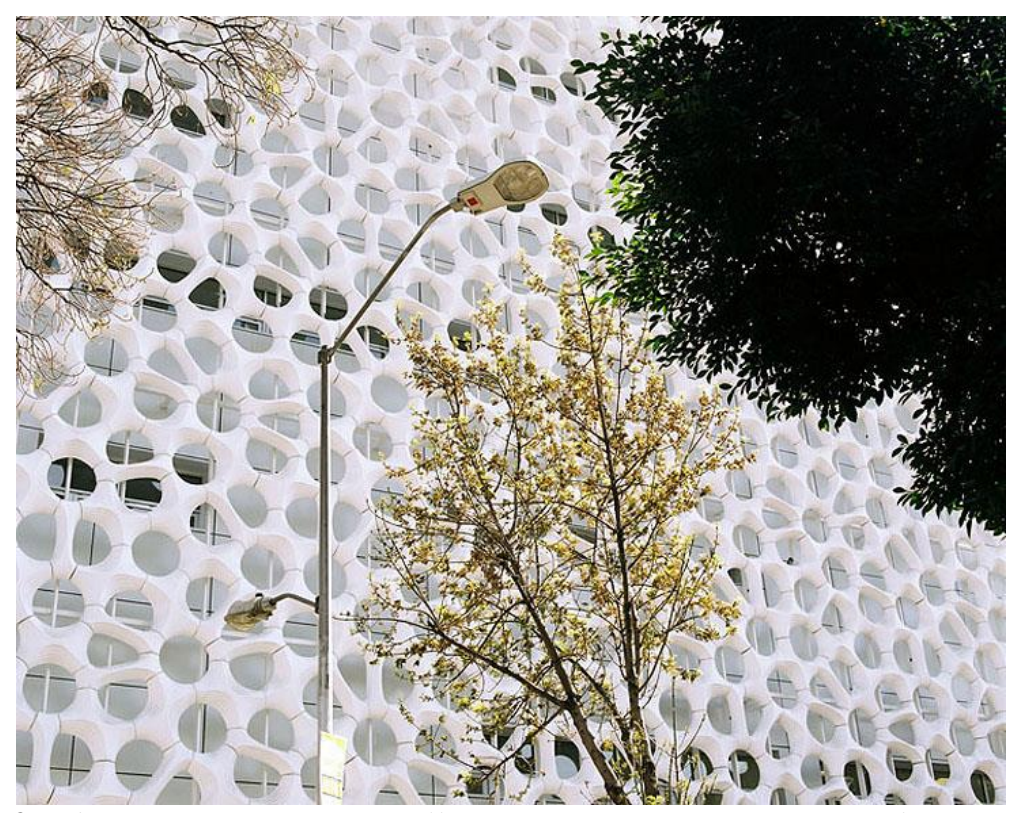

Figure 2. The "smog-eating" installation at Mexico City's Manuel Gea González Hospital (image courtesy of Elegant Embellishments).

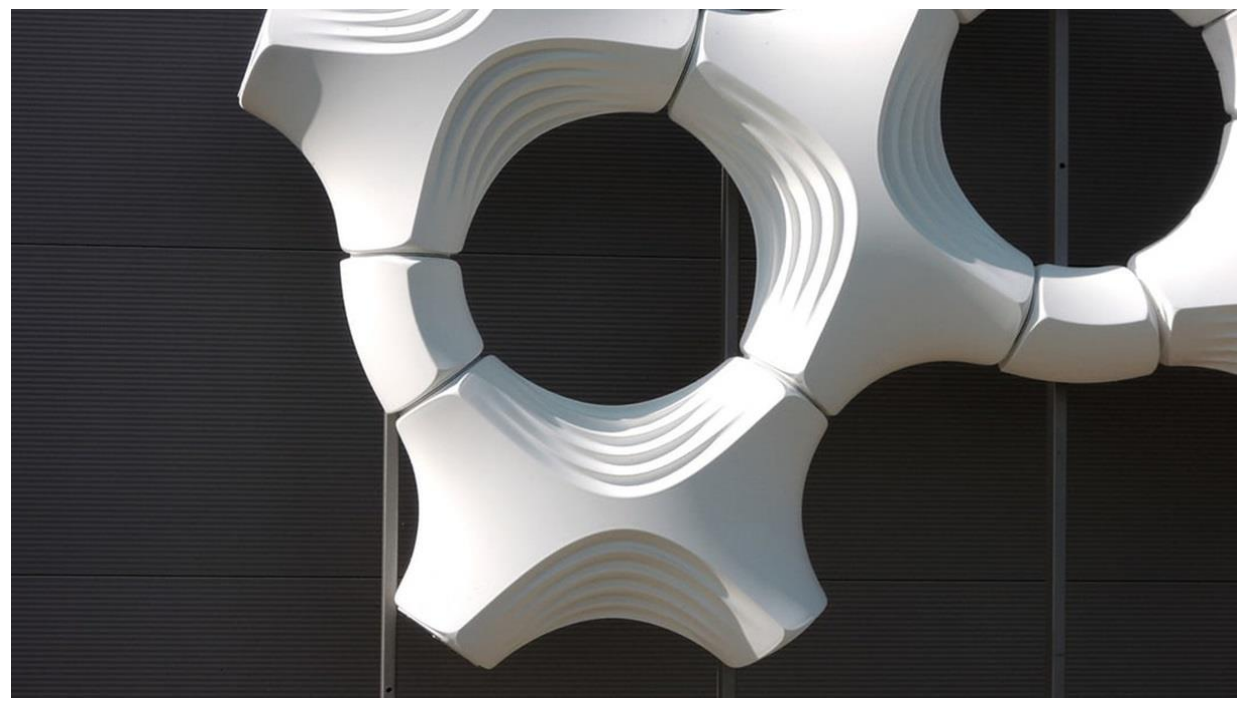

Figure 3. The "smog-eating" installation detail at Mexico City's Manuel Gea González Hospital (image courtesy of Elegant Embellishments).

The medical clinic is shrouded in a 300-foot-long skin of Prosolve370e tiles, created by a German firm called Elegant Embellishments. The innovation depends on a similar procedure: As air channels around the wipe formed structures, UV-light-initiated free radicals decimate any current poisons, leaving the air cleaner for the patients inside. As indicated by Fast Company, even the state of the sun screen is huge: It makes disturbance and hinders wind current around the 
structure, while dissipating the UV light expected to actuate the compound response.

Manuel Gea González Hospital in Mexico City is one such model. The structure's proprietors have made the stride of including another "brown haze eating" façade covering more than 2,500 square meters.

The framework, planned and created by Elegant Embellishments, comprises of thermoformed shells covered in photocatalytic titanium dioxide. This covering responds with light to kill components of air contamination, discrediting the impacts of up to 1,000 vehicles every day as per its engineers.

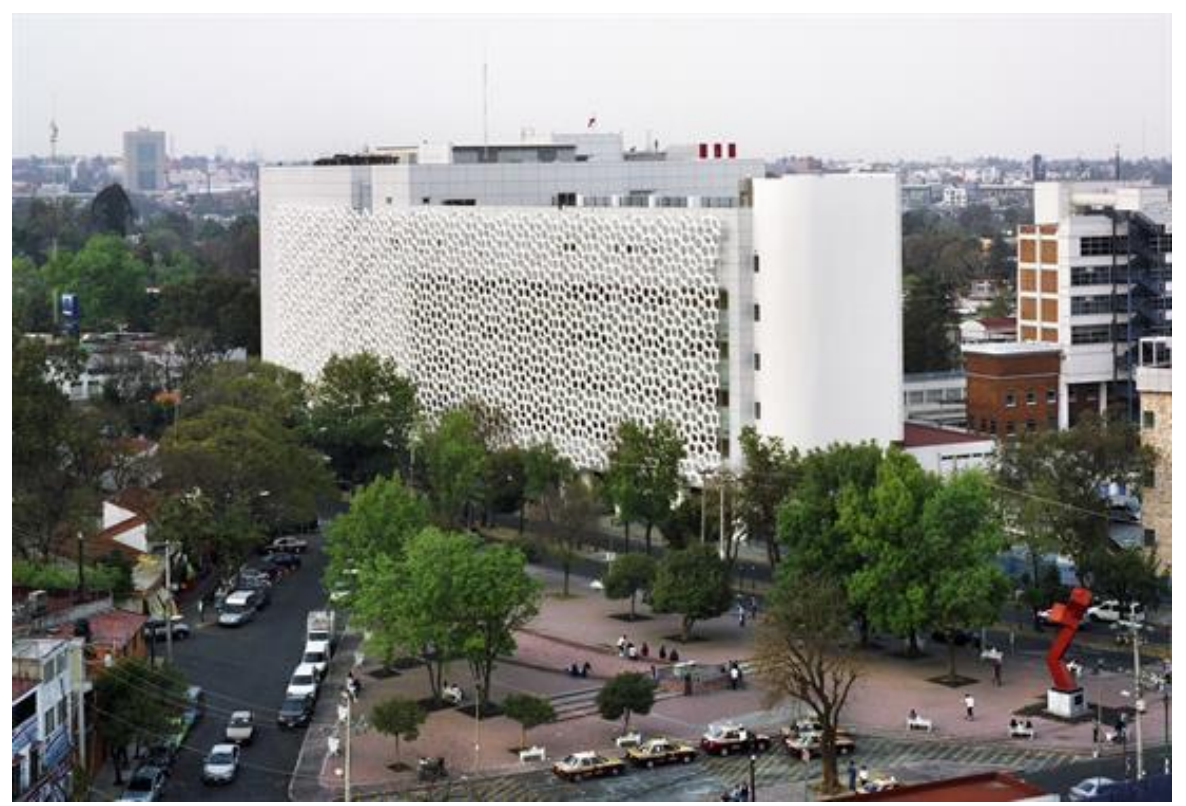

Figure 4. The façade of Manuel Gea González Hospital is said to negate the effects of up to 1,000 cars a day (image courtesy of Elegant Embellishments).

Another model is the amazing Palazzo Italia - or Italy Pavilion - which was the focal point of the 2015 Milan Expo. The structure's six-story outside façade was clad in more than 700 "i.active BIODYNAMIC boards".

Photocatalytic titanium dioxide in the concrete again responds with light to kill certain toxins noticeable all around changing over them to latent salts, consistently filtering the atmosphere.The material adds around 4-5\% to development costs and different instances of its utilization are springing up over the assembled condition; incorporating a photocatalytic roadway in The Netherlands and an "exhaust cloud eating sonnet" imprinted on a flag and held tight the side of a structure in Sheffield, UK. The standard's material contains the photocatalytic substance and is said to neutralize the effect of 20 vehicles every day.

The pennant relates near "reactant attire"; another idea a work in progress by originator Helen Story and polymer scientific expert Tony Ryan that adds titanium dioxide nano-particles to clothing cleanser. 


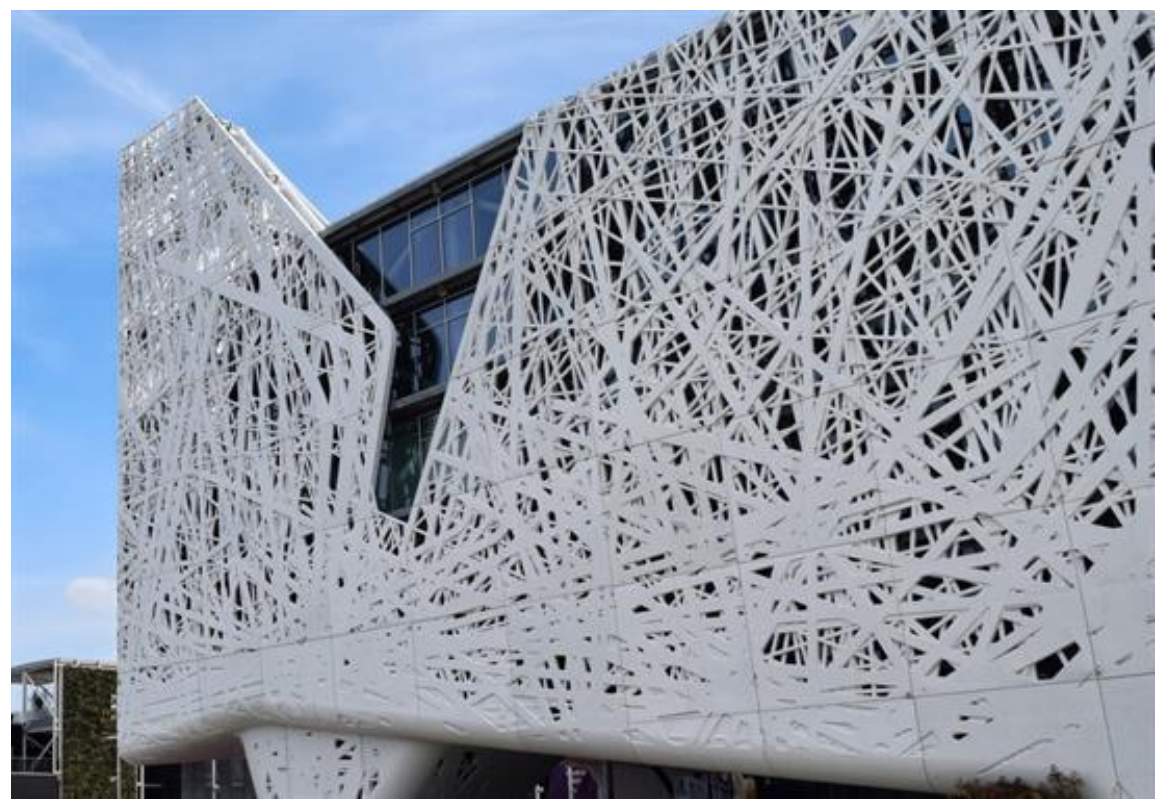

Figure 5. Milan's Palazzo Italia also employs photocatalytic titanium dioxide to neutralise pollutants in the air (images courtesy of Nemesi).

Unmistakably while such "brown haze eating" arrangements are both inventive and powerful, they need far reaching selection so as to have an important effect. The innovation must be applied in adequate scale to coordinate the present degrees of air contamination created the world over on the off chance that it is to effectively check it.

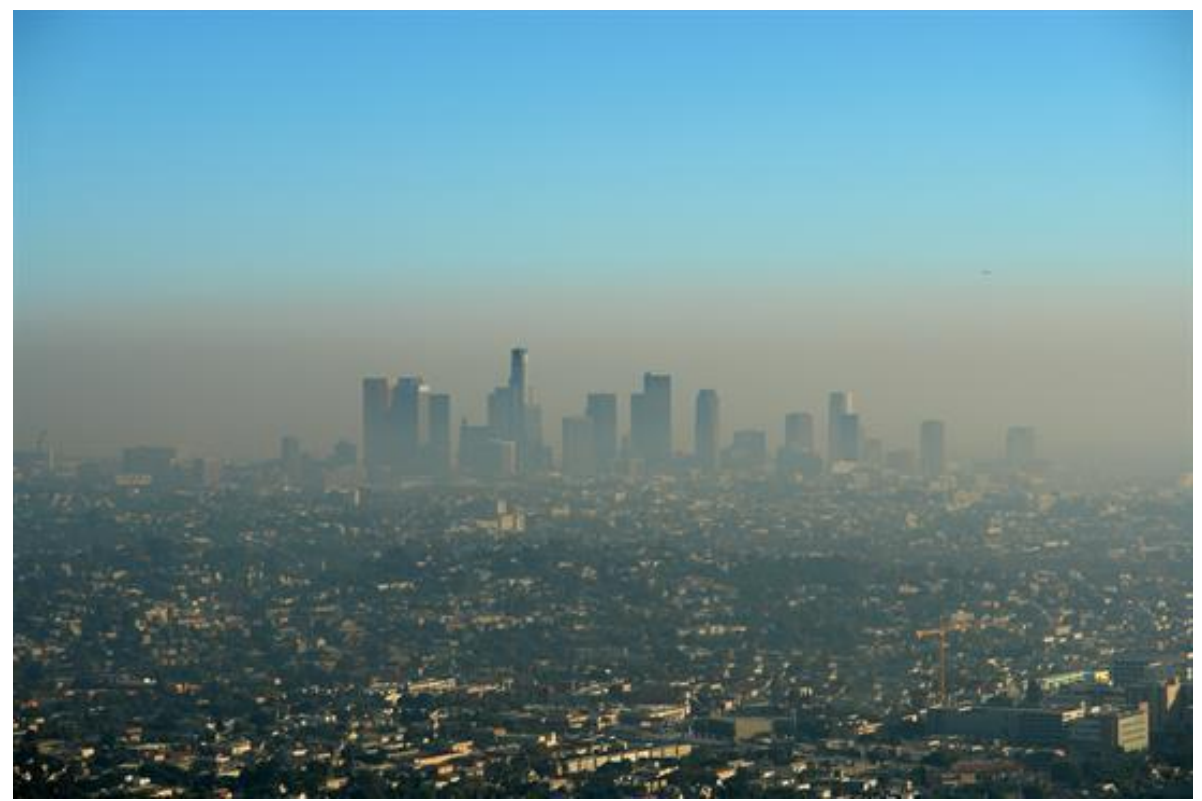

Figure 6. Smog on the Los Angeles skyline. "Smog-eating" solutions need widespread adoption in order to make meaningful impact. 


\section{CONCLUSION AND SUGGESTIONS}

For the first time in the history of architecture, nature and social welfare and non-decorations, styles, luxuries or other superficial elements come first. This new way of thinking, awakens our hope that the bottom line of human society is unconscious, and finally the conviction of what is really important to us is beginning to be created. This new wave of architecture design human society is finally witnessing has a slight tendency to strip away the veil of luxury and complexity, sparking interest in improving the health and mental condition of human society. At the same time, by intervening in the improvement of our social status, it also promotes a global improvement of nature. In my opinon the architectural and more humane revolution begins with the beginnings of sustainable and smart architecture. More than ever, the architects have the chance to make the world a better place.

\section{REFERENCES}

Adams, R. M. (1997) 'Should elhlcs be more llupermnaU', In J. Dancy (ed) Reading Parfir, Oxford: Blackwell Publlshers.

A00 (1999) Amzmlum cnmmucml minding sector g'mfnhrima gm ammmm 1990-2011), chhhcrm; Auslmlmn chenhousc Office.

Alexander, 1:. (1987) A Nam Thnmy of 1mm Dzng'n, New York: Oxford Unlvcrziry Pm»,

APHA (1939) The 17m ("myth ofhmlrhful homing, Cnmmlttcé; on hyglcne and healthful housing, Waahlngum: American Publlc Health Aswcmhm,

Ansmtlc (1952) N1c1m1achmn Erhm, [mm hy M, osrwalll, Indlanapldis: BobhyMcmll $\mathrm{C} 1)$,

Amhenm, R (1993) 'Sketchmg and (he pawholuxy of design', Dexigzn 131m IX(Z): 15719

Baler, K. (1969) 'What 13 valLICY', m K. Baler and N. Reacher (eds) Values and 1111 Future, The Impacl of Technological Change 011 Amwcan Valvus, New York: New York Free Press.

Band, G. (2001) The Archileawml amnion of Envm'mmcmal Control Systems, London and New York. Spun Press.

Baron, 1. (1988) Tirmlmig and Beading, New York: Cambndgc Unlvemty Press.

Bauman, z. (1993) PmrMndum Ethxcs, Oxford: Blackwell Publishers.

Baumun, z, (1995) Llfe rri Fmgmems: Enays m Puerodmfl Mommy, Oxford: Blackwell Publish .

Baumun, z. (2001) The lndwxdwllzcd sham, Cambndge: Pollty Pm, 
Bead-1, 1.. R. (1990) 111111112 Them, Decislon Makmg in Personal rmd Orpcmlzatlorwl Cuntexts. Chlihester: John wrley and sum.

Bengs, c. (1993) 'Sustamable development 7 end hr amour, m T Chill-w (e11) Design, Ecology, Aesthetics, Emir-s, Proceedings afDEcan '95 Spam! Focus Symposium oflmmsymp '95, BadewBaden: The Internaunnal Insmure (or Systems Research and Cybernencs.

Bennerr, R. J. and Charley, R. J. (1978) Eviw'ronmemal Systems- Phllosaphy, Analysis and Crmmll, Lnndnn: Merhuen.

Benncns, H. (2000) 'Envlmnmenml mm and house deslgn in Ausrralm. images (mm theory and pracncc', unpubllshcd rhmis, Unlvcrsity andelmdc.

Bluchhc, G. (1971) '1 luman requlrcmems', Proceeding; $11 \mathrm{mg} 511$ C(mgm» rm Remirh mil) Pmctxcn, Pans»Vcrszulles: International Councll (hr Building Research, Studlc: and Documcnmtlon,

Bouldlng, K. E. (1961) The Image- Knowledge in Llfe and slim), Midngan' The Umver-my $1.1 \mathrm{M}|\mathrm{ch}| \mathrm{gdn}$ Prm.

Bouldmg, K. E, (1978) Ecodyumums A New Theory of Societal Evolution, Beverly H1115, Cahforma: Sage Publlcaunns.

T., Mayne. 2011. Combinatory Urbanism A Realignment of Complex Behavior and Collective Form Flexibound. 448p

M,. Mostafavi. 2010. Ecological Urbanism. Editor G., Doherty. 656p

M., Mostafavi. 2012. In the Life of Cities. 376p

A., Washburn. 2013. The Nature of Urban Design. 264p

J., Lerner. 2011. Urban Acupuncture. 160p

R., Klanten. 2012. Cause and Effect. 240p

E., Lupton, J., Abbott Miller. 2009 Design for a Living World. Editors: J., Abbott Miller, E.,Lupton, A.,Grundberg. 200p

P.,Bellew . 2012. Green House: Green Engineering. 86p 


\title{
THE SUSTAINABLE INTELLIGENT BUILDING SKINS \\ -FACADE IMITATING THE TREE PROCCES OF FILTERING AIR, BIOMIMICRY ARCHITECTURE
}

\author{
Eneida HASKA, Halil Semih ERYILDIZ, Hajri HASKA
}

\begin{abstract}
Summary
In recent years the facades of building have become incrisingly significant due to unconvencional choices of materials and the use of inovative technology. More and more the external surfaces are beeing percived and designet as an integral part of the building. This skin, a protective mantle defines not only the interior but also the adjoining exterior space. It is visiting card of the building. Today's way of doing architecture should be a vision initiative which includes new ways of thinking about the relationship between construction and the environment, discovering new forms and content, and the assertion that the art of construction is in a new phase which will definitely change the way of our living, always in accordance with the language of nature. In this study we will show examples of how new forms of architectural design imitating nature completely change the old fashioned way of design. Especially Intelligent Façade which is a very efficient form of our impact in nature.
\end{abstract}

